\title{
Case Report: Hyperbilirubinemia in Gilbert Syndrome Attenuates Covid-19-Induced Metabolic Disturbances
}

\begin{abstract}
Hayder M. Al-kuraishy ${ }^{1}$, Ali I. Al-Gareeb ${ }^{1}$, Saleh M. Abdullah ${ }^{2}$, Natália Cruz-Martins ${ }^{3,4,5 *}$ and Gaber El-Saber Batiha ${ }^{6 *}$

1 Department of Clinical Pharmacology and Medicine, College of Medicine, Al-Mustansiriya University, Baghdad, Iraq, ${ }^{2}$ Department of Medical Laboratory Technology, Faculty of Applied Medical Sciences, Jazan University, Jazan, Saudi Arabia, ${ }^{3}$ Faculty of Medicine, University of Porto, Porto, Portugal, ${ }^{4}$ Department of Metabolism, Nutrition and Endocrinology, Institute for Research and Innovation in Health (i3S), University of Porto, Porto, Portugal, ${ }^{5}$ Laboratory of Neuropsychophysiology, Faculty of Psychology and Education Sciences, University of Porto, Porto, Portugal, ${ }^{6}$ Department of Pharmacology and Therapeutics, Faculty of Veterinary Medicine, Damanhour University, Damanhour, Egypt
\end{abstract}

\section{OPEN ACCESS}

Edited by:

Shuyang Zhang,

Peking Union Medical College

Hospital, China

Reviewed by:

Yasumasa lkeda,

Tokushima University, Japan

Di Ren,

University of South Florida,

United States

*Correspondence:

Natália Cruz-Martins

ncmartins@med.up.pt

Gaber El-Saber Batiha

gaberbatiha@gmail.com

Specialty section:

This article was submitted to Cardiovascular Metabolism,

a section of the journal

Frontiers in Cardiovascular Medicine

Received: 15 December 2020 Accepted: 20 January 2021

Published: 17 February 2021

Citation:

Al-kuraishy HM, Al-Gareeb Al, Abdullah SM, Cruz-Martins N and Batiha GE-S (2021) Case Report:

Hyperbilirubinemia in Gilbert

Syndrome Attenuates

Covid-19-Induced Metabolic

Disturbances.

Front. Cardiovasc. Med. 8:642181

doi: 10.3389/fcrm.2021.642181
Gilbert syndrome (GS) is a liver disorder characterized by non-hemolytic unconjugated hyperbilirubinemia. On the other hand, Coronavirus disease 2019 (Covid-19) is a recent viral infectious disease presented as clusters of pneumonia, triggered by the severe acute respiratory syndrome-coronavirus 2 (SARS-CoV-2). Little is known on the association between SARS-CoV-2 and GS, despite different studies have recently stated a link between hyperbilirubinemia and SARS-CoV-2 severity. In this case-report study we described a 47-year-old man, a known case of GS since the age of 4, presented to the emergency department with fever $\left(39.8^{\circ} \mathrm{C}\right)$, dry cough, dyspnea, headache, myalgia, sweating and jaundice diagnosed with Covid-19-induced pneumonia. Interestingly, GS patient exhibited a rapid clinical recovery and short hospital stay compared to other SARS-CoV-2 positive patient, seeming that hyperbilirubinemia may exert a protective effect of against Covid-19 induced-cardiometabolic disturbances. Data obtained here underlines that the higher resistance against Covid-19 evidenced by the GS patient seems to be due to the antioxidant, anti-inflammatory, and antiviral effects of unconjugated bilirubin.

\section{Keywords: gilbert syndrome, SARS-CoV-2, hyperbilirubinemia, COVID-19, metabolic disease}

\section{INTRODUCTION}

Gilbert syndrome (GS) is a chronic liver disorder characterized by non-hemolytic unconjugated hyperbilirubinemia due to defect in the hepatic uptake of unconjugated bilirubin, which was first described by Augustin Gilbert in 1901 (1). GS is also called simple familial jaundice or icterus intermittent juvenilis, affects $5-10 \%$ of general population, being most common in male (2). Clinically, GS is presented with mild recurrent jaundice, fatigue and abdominal pain provoked by stress, infection, and menstruation. GS results from reduction in bilirubin uridine diphosphate glucuronyltransferase enzyme activity due to mutation in the UGT1A1 gene. There are more than 100 variants of UGT1A1 gene associated with GS phenotype, and generally, there is no effective treatment for GS, despite phenobarbital may be used in severe cases (3). Previously, 
Maruhashi et al. (4) reported that hyperbilirubinemia in GS is associated with a cardioprotective effect attributed to the antioxidant and vasodilator effects of bilirubin.

On the other hand, coronavirus disease 2019 (Covid19), a recent viral infectious disease presented as clusters of pneumonia and caused by the severe acute respiratory syndrome coronavirus-2 (SARS-CoV-2), has triggered a huge attention among both medical and scientific communities with the intent of discovering an effective therapeutic agent (5). The clinical spectrum of Covid-19 is asymptomatic or mild flu-like illness in around $85 \%$, mainly in young adults; however, $10 \%$ of cases develop a severe disease with risk of development of acute respiratory distress syndrome (ARDS) (6). However, in severe cases, Covid-19 may leads to extra-pulmonary manifestations, like acute cardiac injury, arrhythmias, acute kidney injury, acute brain injury, endocrine failure, multiple organ failure, metabolic disturbances, and even death (7). In this sense, as Covid-19 pandemic has full-grown public health issues, here we present a case-report study of a patient with GS who gets infected by the SARS-CoV-2. This case is particularly relevant regarding the ameliorative role of hyperbilirubinemia in GS patients during Covid-19 pneumonia.

\section{CASE REPORT}

\section{Presenting Concerns}

A 47-year-old man, a known case of GS since age of 4-year, presented to the emergency department with fever, dry cough, dyspnea, headache, myalgia, sweating, jaundice, and generalized poor health condition without response to the empiric antibiotics and analgesics for about 3 days. Besides, a 53-years-old man presented with fever $\left(38.9^{\circ} \mathrm{C}\right)$, cough, headache, malaise and sweating diagnosed as Covid-19 pneumonia was regarded as a control. Informed verbal consent was attained from both patients, and this study was approved (MRT 7 August 2020) by the Scientific Editorial Board in College of Medicine, AlMustansiriyia University, Baghdad, Iraq.

\section{Clinical and Laboratory Findings}

General physical examination showed a conscious and febrile patient $\left(39.8^{\circ} \mathrm{C}\right)$, with jaundice and poor health status. His blood pressure was $140 / 90 \mathrm{mmHg}$, heart rate was 110 beats/min and body mass index (BMI) of $33.73 \mathrm{~kg} / \mathrm{m}^{2}$ and hypoxemia $\left(\mathrm{SaO}_{2} 91 \%\right)$. Chest X-ray and chest computed tomography (CT) scan illustrated bilateral prominent bronchovascular marking and ground-glass opacities, respectively, suggestive of Covid19-induced pneumonia (Figure 1). Radiological score was used to determine the radiological severity according to Wasilewski et al. (8).

Anti-SARS-CoV-2 antibody (IgM) was positive $(2.9 \mathrm{U} / \mathrm{mL})$ for Covid-19 patient with GS compared with $(2.89 \mathrm{U} / \mathrm{mL})$ for Covid19 patient only, suggesting an acute SARS-CoV-2 infection in both. Complete blood count (CBC), fasting blood glucose (FBG), glycated hemoglobin (HbAlc), blood urea, serum creatinine, Creactive protein (CRP), D-dimer, serum lactate dehydrogenase $(\mathrm{LDH})$, and serum ferritin were done at the laboratory unit. Preliminary investigations showed high FBG (165 mg/dL),

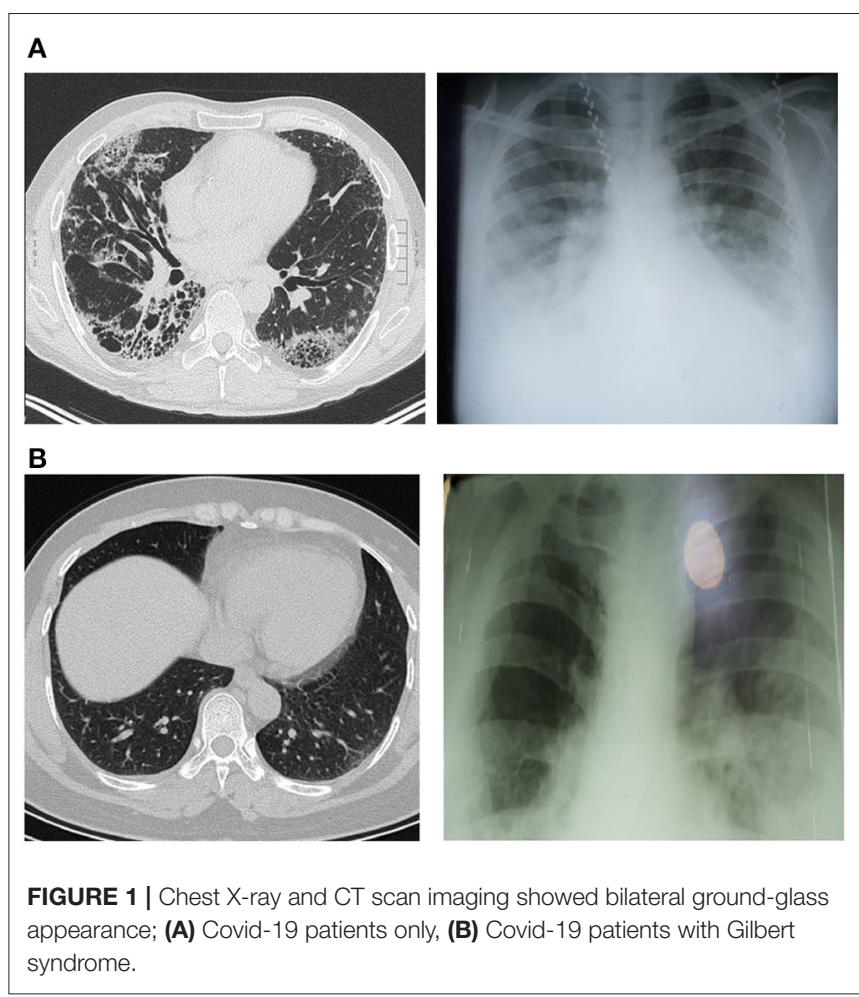

HbAlc (5.5\%), total serum bilirubin $(6.8 \mathrm{mg} / \mathrm{dL})$, unconjugated bilirubin $(6 \mathrm{mg} / \mathrm{dL})$, conjugated bilirubin $(0.8 \mathrm{mg} \mathrm{mg} / \mathrm{dL})$, and high white cell counts $(16.073 / \mu \mathrm{L})$ with lymphopenia $(9.12 \mu / \mathrm{L})$. Similarly, the inflammatory biomarkers were increased in regard to reference ranges. D-dimer $(14.000 \mathrm{ng} / \mathrm{mL})$, CRP $(243 \mathrm{mg} / \mathrm{L})$, ferritin $(654 \mathrm{ng} / \mathrm{mL})$, and $\mathrm{LDH}(674 \mathrm{U} / \mathrm{L})$.

Liver function test and ultrasonography imaging were done to exclude liver injury. Taken together, clinical findings, radiological examinations and laboratory findings of this GS patient with Covid-19 were compared with a matched COVID-19 patient without GS at time of hospitalization (Table 1).

Both patients were treated with the analgesic acetaminophen (500 mg/day), azithromycin (500 mg/day) for the first 5 days, ivermectin (12 mg/day), famotidine (40 mg/day), soluble insulin (10 units) 3 times/day, and montelukast (10 mg/day). Besides oxygen therapy by high flow nasal cannula for 10 days, patients also received subcutaneous enoxaparin (60 mg/day) during the hospitalization period as a prophylaxis against venous thromboembolism.

\section{Follow-Up and Outcomes}

Following 3 weeks of management, all laboratory investigations, radiological, and clinical findings return to normal except of unconjugated bilirubin (Table 2) and the patient was discharged to home. Particularly, the GS patient showed a rapid clinical improvement as compared to the Covid-19 patient without GS during the hospitalization period.

An outpatient follow-up through mobile dial-up within 2 weeks following discharge disclosed a complete recovery and the GS patient returned to his prior physical fitness and normal daily activities. 
TABLE 1 | Cardiometabolic and inflammatory profiles of GS patient COVID-19 positive compared to a control patient at time of admission.

\begin{tabular}{|c|c|c|c|c|}
\hline Variables & $\begin{array}{l}\text { Reference } \\
\text { range }\end{array}$ & $\begin{array}{c}\text { COVID-19 } \\
\text { patient with } \\
\text { GS }\end{array}$ & $\begin{array}{l}\text { COVID-19 } \\
\text { patient }\end{array}$ & $\begin{array}{c}\% \\
\text { Difference }\end{array}$ \\
\hline $\mathrm{BMI}\left(\mathrm{kg} / \mathrm{m}^{2}\right)$ & $20-25$ & 33.73 & 34.71 & 2.86 \\
\hline SBP (mmHg) & $110-120$ & 140 & 153 & 8.87 \\
\hline DBP (mmHg) & 70-90 & 90 & 92 & 2.19 \\
\hline $\begin{array}{l}\text { Covid-19 lgM } \\
(\mathrm{U} / \mathrm{mL})\end{array}$ & $0.9-1.1$ & 2.9 & 2.89 & 0.34 \\
\hline $\begin{array}{l}\text { Covid-19 lgG } \\
(\mathrm{U} / \mathrm{mL})\end{array}$ & $0.9-1.1$ & 0.00 & 0.00 & 0.00 \\
\hline $\mathrm{SaO}_{2} \%$ & 95-99 & 91 & 89 & 1.11 \\
\hline TSB (mg/dL) & $0.2-1.0$ & 6.8 & 0.8 & 157.89 \\
\hline $\begin{array}{l}\text { Conjugated } \\
\text { bilirubin (mg/dL) }\end{array}$ & $0.1-0.3$ & 0.8 & 0.7 & 13.33 \\
\hline $\begin{array}{l}\text { Un-conjugated } \\
\text { bilirubin (mg/dL) }\end{array}$ & $0.1-0.7$ & 6.0 & 0.1 & 193.44 \\
\hline $\mathrm{FBG}(\mathrm{mg} / \mathrm{dL})$ & $70-90$ & 165 & 199 & 18.68 \\
\hline HbA1c (\%) & $4.5-5.5$ & 5.5 & 5.9 & 7.01 \\
\hline Blood urea & $20-40$ & 41 & 39.7 & 3.22 \\
\hline Serum creatinine & $0.5-1.5$ & 1.2 & 1.1 & 8.69 \\
\hline CRP (mg/L) & $0.5-200$ & 243 & 422 & 53.83 \\
\hline D-dimer (ng/mL) & $50-10.000$ & 14.000 & 22.000 & 44.44 \\
\hline Ferritin (ng/mL) & $20-250$ & 654 & 907.84 & 32.50 \\
\hline LDH (U/L) & $230-460$ & 674 & 795.21 & 16.50 \\
\hline $\mathrm{Hb}(\mathrm{g} / \mathrm{dL})$ & $12-14$ & 13.8 & 14.36 & 3.97 \\
\hline WBC ( $\mu / L)$ & $4,000-11,000$ & 16.073 & 15.74 & 2.09 \\
\hline Lymphocytes \% & $20-40$ & 9.12 & 7.53 & 19.09 \\
\hline Neutophils \% & $40-80$ & 85.31 & 89.45 & 4.73 \\
\hline Radiological score & $1-5$ & 4 & 5 & 22.22 \\
\hline
\end{tabular}

Data presented as number and \%, BMI, body mass index; SBP, systolic blood pressure; $D B P$, diastolic blood pressure; TSB, total serum bilirubin; FBG, fasting blood glucose; HbA1c, glycated hemoglobin.

\section{CLINICAL COURSE SUMMARY}

At time of hospitalization, both Covid-19 patients with or without GS presented comparable clinical presentations, like fever, headache, sweating, dry cough, fatigue, and generalized poor health status. However, these clinical features were less severe in Covid-19 patient with GS compared with Covid-19 patient only. In addition to high serum levels of unconjugated bilirubin in Covid-19 patient with GS, both laboratory and radiological findings were better as compared with Covid-19 patient only. In the management period, patients received the same course of supportive therapy, antibiotics, anticoagulants, and other drugs. During hospitalization period, the fasting blood glucose (FBG) was elevated in both Covid-19 patients $(\mathrm{FBG}=165 \mathrm{mg} / \mathrm{dL}$ in GS, $199 \mathrm{mg} / \mathrm{dL}$ in Covid-19 control), managed through using soluble insulin subcutaneously 10 IU/day with frequent monitoring of FBG. In particular, Covid19 patient with GS presented with a less needed for oxygen therapy compared with control Covid-19 patients who was more dependent on oxygen therapy. Near the end of hospitalization period, Covid-19 patient with GS showed a rapid clinical
TABLE 2 | Cardiometabolic and inflammatory profiles of GS patient COVID-19 positive compared to a control patient at time of discharge.

\begin{tabular}{|c|c|c|c|c|}
\hline Variables & $\begin{array}{l}\text { Reference } \\
\text { range }\end{array}$ & $\begin{array}{l}\text { Covid-19 } \\
\text { with GS }\end{array}$ & $\begin{array}{l}\text { Covid-19 } \\
\text { patient }\end{array}$ & $\begin{array}{c}\% \\
\text { Difference }\end{array}$ \\
\hline BMI $\left(\mathrm{kg} / \mathrm{m}^{2}\right)$ & $20-25$ & 32.65 & 34.71 & 6.11 \\
\hline $\mathrm{SBP}(\mathrm{mmHg})$ & $110-120$ & 119 & 143 & 18.32 \\
\hline $\mathrm{DBP}(\mathrm{mmHg})$ & 70-90 & 79 & 82 & 3.72 \\
\hline $\begin{array}{l}\text { Covid-19 IgM } \\
(\mathrm{U} / \mathrm{mL})\end{array}$ & $0.9-1.1$ & 0.9 & 0.89 & 1.11 \\
\hline $\begin{array}{l}\text { Covid-19 lgG } \\
(\mathrm{U} / \mathrm{mL})\end{array}$ & $0.9-1.1$ & 7.84 & 6.01 & 26.42 \\
\hline $\mathrm{SaO}_{2} \%$ & $95-99$ & 98 & 95 & 3.10 \\
\hline TSB (mg/dL) & $0.2-1.0$ & 3.4 & 0.8 & 123.81 \\
\hline $\begin{array}{l}\text { Conjugated } \\
\text { bilirubin (mg/dL) }\end{array}$ & $0.1-0.3$ & 0.4 & 0.7 & 54.54 \\
\hline $\begin{array}{l}\text { Un-conjugated } \\
\text { bilirubin (mg/dL) }\end{array}$ & $0.1-0.7$ & 3.0 & 0.1 & 187.09 \\
\hline FBG (mg/dL) & $70-90$ & 95 & 179 & 61.31 \\
\hline $\mathrm{HbA1c}(\%)$ & $4.5-5.5$ & 5.5 & 5.9 & 7.01 \\
\hline Blood urea & $20-40$ & 33 & 34.7 & 5.02 \\
\hline Serum creatinine & $0.5-1.5$ & 1.3 & 1.2 & 8 \\
\hline CRP (mg/L) & $0.5-200$ & 22 & 122 & 138.88 \\
\hline D-dimer (ng/mL) & 50-10.000 & 452 & 631.71 & 33.16 \\
\hline Ferritin (ng/mL) & $20-250$ & 105 & 207.84 & 65.74 \\
\hline LDH (U/L) & $230-460$ & 321 & 395.21 & 20.72 \\
\hline $\mathrm{Hb}(\mathrm{g} / \mathrm{dL})$ & $12-14$ & 13.8 & 14.36 & 3.97 \\
\hline WBC $(\mu / L)$ & $4,000-11,000$ & 8.832 & 9.44 & 6.65 \\
\hline Lymphocytes \% & $20-40$ & 33.7 & 22.53 & 39.72 \\
\hline Neutophils \% & $40-80$ & 72.88 & 80.45 & 9.87 \\
\hline Radiological score & $1-5$ & 1 & 2 & 66.66 \\
\hline
\end{tabular}

Data presented as number and \%, BMI, body mass index; SBP, systolic blood pressure; $D B P$, diastolic blood pressure; TSB, total serum bilirubin; FBG, fasting blood glucose; HDA1c, glycated hemoglobin.

improvement as compared to the Covid-19 patient without GS. At the third week of disease management, clinical, radiological and laboratory findings were re-evaluated. All investigations and clinical findings return to normal with exception of unconjugated bilirubin, which remained higher in Covid-19 patient with GS $(3 \mathrm{mg} / \mathrm{dL})$ as compared with that in control Covid-19 patient $(1 \mathrm{mg} / \mathrm{dL})$. Both patients were discharged to home with complete recovery and returned to normal daily activities.

\section{DISCUSSION}

To our knowledge, this is the first reported case study of Covid-19 in a patient with GS. The GS patient with Covid-19 showed a rapid clinical improvement and short hospital stay as compared with a Covid-19 patient. Indeed, it has been proven that bilirubin exerts potent antioxidant effects which might alleviates Covid-19 induced-oxidative stress (9). Also, it has been reported that bilirubin has cardioprotective effects, improves endothelial function and provokes the nitric oxide (NO) release (10), thus, preventing from endothelial dysfunction and cardiovascular 
complications in COVID-19 (11), as evident of hypertension in Covid-19 case compared to GS patient with Covid-19. Unfortunately, oxidative stress profile and endogenous antioxidant capacity were not measured in the present study to confirm the antioxidant potential of unconjugated bilirubin in Covid-19.

Liu et al. (12) found that SARS-CoV-2 infection leads to downregulation of angiotensin converting enzyme 2 (ACE2) causing a reduction in the vasodilator angiotensins (Ang 1-7 and Ang 1-9) and augmenting of vasoconstrictor angiotensin II (AngII). These changes per se lead to acute lung injury (ALI), cardiovascular and metabolic disturbances in Covid-19 patients. Recently, Novák et al. (13) reported that high bilirubin levels attenuate the metabolic disorders through inhibition and attenuation of renin-angiotensin system (RAS). Besides, bilirubin has a protective effect against experimental ALI through inhibition of ischemic-reperfusion injury and exerting anti-proliferative effects (14). Therefore, high serum bilirubin level in patients with GS may lessen ALI and the development of ARDS through attenuation of AngII induced-pulmonary vasoconstriction and hyper-inflammation (15). These findings might explain a lower CT score 4 in Covid-19 with GS as compared with control Covid-19 score 5 .

Lin et al. (16) also illustrated that bilirubin inhibits the nodlike receptor pyrin3 (NLRP3) inflammasomes over-activation through myeloperoxidase inhibition and subsequent reduction of inflammatory cytokines release. Thereby, high serum bilirubin levels in patients with GS may attenuate the development of cytokine storm during Covid-19 progression via inhibiting the release of interleukin (IL)-6, tumor necrosis factor (TNF)- $\alpha$ and IL-1 $\beta$ (17). These findings might explain the low rate of inflammatory biomarkers in GS patient with Covid-19 compared to the Covid-19 patient without GS. These protective effects of high bilirubin in GS are lacking in patients with Covid-19 pneumonia without GS. It has been shown that uncontrolled high pro-inflammatory cytokines, oxidative stress and unrestrained activation of NLRP3 inflammasomes contribute for development of ALI and progression of Covid-19 severity $(18,19)$.

Interestingly, fasting blood glucose (FBG) was increased at time of admission due to SARS-CoV-2 induced insulin resistance and transient pancreatic $\beta$-cells dysfunction. (20). However, FBG seem to be lower in Covid-19 patient with GS, since high unconjugated bilirubin in GS improves FBG and hyperinsulinemia through activation of peroxisome proliferative activated receptor alpha (PPAR- $\alpha)(21)$.

On the other hand, Santangelo et al. (22) disclosed that endogenous bilirubin has antiviral property against human herpes simplex virus type 1 (HSV-1), hepatitis C virus and enterovirus EV71 via up-regulation of mitogen activated protein kinase (MAPK) and c-Jun N-terminal (JNK). Both of MAPK and JNK are involved in the replication and pathogenesis of SARS$\mathrm{CoV}-2$ and other coronaviruses (23). Therefore, bilirubin may be the future endogenous agent against SARS-CoV-2. Nonetheless, Liu et al. (24) found that serum bilirubin levels are correlated with Covid-19 induced-liver injury and hemolysis, but the author ignored the antioxidant and anti-inflammatory properties of bilirubin.

The present case-report study had some limitations, including genetic sequence genotype and genetic information of family of patient with GS was not evaluated, relevant past interventions were not recorded, and antioxidant profile was not estimated. Even though this study is regarded as a baseline for future clinical trials and large-scale prospective to confirm the protective effect of unconjugated bilirubin against Covid-19.

\section{CONCLUSION}

Taken together, data obtained in this case report study shed light on the new modality for COVID-19 therapy through modulation of bilirubin metabolism. As well, high bilirubin levels in the GS patient with COVID-19 conferred a protective effect against COVID-19-derived cardiometabolic disturbances. In fact, the GS patient revealed higher resistance against COVID-19 associated cardiometabolic disturbances compared to the other COVID-19 patient without GS, directly linked to the antioxidant, anti-inflammatory and antiviral effects of unconjugated bilirubin. However, we cannot sketch any definitive conclusion from our observation; thus prospective, randomized, controlled studies are recommended in this regard.

\section{DATA AVAILABILITY STATEMENT}

The raw data supporting the conclusions of this article will be made available by the authors, without undue reservation.

\section{ETHICS STATEMENT}

The studies involving human participants were reviewed and approved by Al-Mustansiriyia University. The patients/participants provided their written informed consent to participate in this study. Written informed consent was obtained from the individual(s) for the publication of any potentially identifiable images or data included in this article.

\section{AUTHOR CONTRIBUTIONS}

All authors listed have made a substantial, direct and intellectual contribution to the work, and approved it for publication.

\section{ACKNOWLEDGMENTS}

To all members in College of Medicine, Al-Mustansiyria University. NC-M acknowledges the Portuguese Foundation for Science and Technology under the Horizon 2020 Program (PTDC/PSI-GER/28076/2017). 


\section{REFERENCES}

1. Fretzayas A, Moustaki M, Liapi O, Karpathios T. Gilbert syndrome. Eur J. Pediatrics. (2012) 171:11. doi: 10.1007/s00431-011-1641-0

2. Aiso M, Yagi M, Tanaka A, Miura K, Miura R, Arizumi $T$, et al. Gilbert syndrome with concomitant hereditary spherocytosis presenting with moderate unconjugated hyperbilirubinemia. Int Med. (2017) 56:6614. doi: 10.2169/internalmedicine. 56.7362

3. Ha VH, Jupp J, Tsang RY. Oncology drug dosing in gilbert syndrome associated with UGT 1A1: a summary of the literature. Pharmacotherapy. (2017) 37:956-72. doi: 10.1002/phar.1946

4. Maruhashi T, Soga J, Fujimura N, Idei N, Mikami S, Iwamoto Y, et al. Hyperbilirubinemia, augmentation of endothelial function, and decrease in oxidative stress in Gilbert syndrome. Circulation. (2012) 126:598603. doi: 10.1161/CIRCULATIONAHA.112.105775

5. Al-Kuraishy HM, Hussien NR, Al-Naimi MS, Al-Buhadily AK, AlGareeb AI, Lungnier C. Is ivermectin-azithromycin combination the next step for COVID-19? Biomed Biotechnol Res J. (2020) 4:101. doi: 10.4103/bbrj.bbrj_103_20

6. García LF. Immune response, inflammation, and the clinical spectrum of COVID-19. Front Immunol. (2020) 11:1441. doi: 10.3389/fimmu.2020.01441

7. Johnson KD, Harris C, Cain JK, Hummer C, Goyal H, Perisetti A. Pulmonary and extra-pulmonary clinical manifestations of COVID-19. Front Med. (2020) 7:526. doi: 10.3389/fmed.2020.00526

8. Wasilewski PG, Mruk B, Mazur S, Półtorak-Szymczak G, Sklinda K, Walecki J. COVID-19 severity scoring systems in radiological imaging-a review. Polish J Radiol. (2020) 85:e361. doi: 10.5114/pir.2020.98009

9. Luckring EJ, Parker PD, Hani H, Grace MH, Lila MA, Pierce JG, et al. In vitro evaluation of a novel synthetic bilirubin analog as an antioxidant and cytoprotective agent for pancreatic islet transplantation. Cell Transplant. (2020) 29:0963689720906417. doi: 10.1177/09636897209 06417

10. Bakrania B, Du Toit EF, Ashton KJ, Wagner KH, Headrick JP, Bulmer AC. Chronically elevated bilirubin protects from cardiac reperfusion injury in the male Gunn rat. Acta Physiol. (2017) 220:461-70. doi: 10.1111/apha.12858

11. Long B, Brady WJ, Koyfman A, Gottlieb M. Cardiovascular complications in COVID-19. Am J Emerg Med.? (2020) 38:15047. doi: $10.1016 /$ j.ajem.2020.04.048

12. Liu N, Hong Y, Chen RG, Zhu HM. High rate of increased level of plasma Angiotensin II and its gender difference in COVID-19: an analysis of 55 hospitalized patients with COVID-19 in a single hospital, Wuhan, China. medRxiv [Preprint]. (2020) doi: 10.21203/rs.3.rs-51770/v1

13. Novák P, Jackson AO, Zhao GJ, Yin K. Bilirubin in metabolic syndrome and associated inflammatory diseases: new perspectives. Life Sci. (2020) 257:118032. doi: 10.1016/j.lfs.2020.118032

14. Leem AY, Kim YS, Lee JH, Kim TH, Kim HY, Oh YM, et al. Serum bilirubin level is associated with exercise capacity and quality of life in chronic obstructive pulmonary disease. Respir Res. (2019) 20:279. doi: 10.1186/s12931-019-1241-5

15. Karmouty-Quintana H, Thandavarayan RA, Keller SP, Sahay S, Pandit LM, Akkanti B. Emerging mechanisms of pulmonary vasoconstriction in SARSCoV-2-induced Acute Respiratory Distress Syndrome (ARDS) and potential therapeutic targets. Int J Mol Sci. (2020) 21:8081. doi: 10.3390/ijms21218081

16. Lin Y, Wang S, Yang Z, Gao L, Zhou Z, Yu P, et al. Bilirubin alleviates aluminduced peritonitis through inactivation of NLRP3 inflammasome. Biomed Pharmacother. (2019) 116:108973. doi: 10.1016/j.biopha.2019.108973

17. Tran DT, Jeong YY, Kim JM, Bae HB, Son SK, Kwak SH. The antiinflammatory role of bilirubin on "Two-Hit" sepsis animal model. Int J Mol Sci. (2020) 21:8650. doi: 10.3390/ijms21228650

18. Ragab D, Salah Eldin H, Taeimah M, Khattab R, Salem R. The COVID19 cytokine storm; what we know so far. Front Immunol. (2020) 11:1446. doi: 10.3389/fimmu.2020.01446

19. de Rivero Vaccari JC, Dietrich WD, Keane RW, de Rivero Vaccari JP. The inflammasome in times of COVID-19. Front Immunol. (2020) 11:2474. doi: 10.3389/fimmu.2020.583373

20. Taneera J, El-Huneidi W, Hamad M, Mohammed AK, Elaraby E, Hachim MY. Expression profile of SARS-CoV-2 host receptors in human pancreatic islets revealed upregulation of ACE2 in diabetic donors. Biology. (2020) 9:215. doi: 10.3390/biology9080215

21. Hinds TD Jr, Stec DE. Bilirubin, a cardiometabolic signaling molecule. Hypertension. (2018) 72:78895. doi: 10.1161/HYPERTENSIONAHA.118.11130

22. Santangelo R, Mancuso C, Marchetti S, Di Stasio E, Pani G, Fadda G. Bilirubin: an endogenous molecule with antiviral activity in vitro. Front Pharmacol. (2012) 3:36. doi: 10.3389/fphar.2012.00036

23. Wehbe Z, Hammoud S, Soudani N, Zaraket H, El-Yazbi A, Eid AH. Molecular insights into SARS COV-2 interaction with cardiovascular disease: role of RAAS and MAPK signaling. Front Pharmacol. (2020) 11:836. doi: 10.3389/fphar.2020.00836

24. Liu Z, Li J, Long W, Zeng W, Gao R, Zeng G, et al. Bilirubin levels as potential indicators of disease severity in coronavirus disease patients: a retrospective cohort study. Front Med. (2020) 7:598870. doi: 10.3389/fmed.2020.598870

Conflict of Interest: The authors declare that the research was conducted in the absence of any commercial or financial relationships that could be construed as a potential conflict of interest.

Copyright (c) 2021 Al-kuraishy, Al-Gareeb, Abdullah, Cruz-Martins and Batiha. This is an open-access article distributed under the terms of the Creative Commons Attribution License (CC BY). The use, distribution or reproduction in other forums is permitted, provided the original author(s) and the copyright owner(s) are credited and that the original publication in this journal is cited, in accordance with accepted academic practice. No use, distribution or reproduction is permitted which does not comply with these terms. 